The relationship between the chemical, mechanical and geometrical properties of basalt fibre

\title{
Ralph, C
}

http://hdl.handle.net/10026.1/12371

\subsection{7/0040517518805376}

Textile Research Journal

SAGE Publications

All content in PEARL is protected by copyright law. Author manuscripts are made available in accordance with publisher policies. Please cite only the published version using the details provided on the item record or document. In the absence of an open licence (e.g. Creative Commons), permissions for further reuse of content should be sought from the publisher or author. 


\title{
The relationship between the chemical, mechanical and geometrical properties of basalt fibre
}

Declarations of interest: The authors declare that they have no conflict of interest.

\begin{abstract}
This paper aims to understand the relationship between the chemical, mechanical and geometrical properties by investigating basalt fibre from three commercial manufacturers and comparing to an industry standard glass fibre. The chemical composition of fibre was investigated through XRF, highlighting that basalt and glass fibres are comprised by a similar elemental composition with the main differences being variations in content of primary elements. A significant correlation between the ceramic content of basalt and its tensile properties is demonstrated, with a primary dependence on $\mathrm{Al}_{2} \mathrm{O}_{3}$ content. Single fibre tensile tests at various lengths and two-way ANOVA revealed that the tensile strength and modulus were highly dependent on fibre length with a minor dependence on manufacturer. Results demonstrate that basalt has a higher tensile strength and a comparable modulus to E-glass. Considerable improvements in quality of basalt fibre manufacture are demonstrated over a three year period through geometrical analysis, showing reduction in standard deviation of fibre diameter from 1.33 to 0.61 , comparable to tested glass fibre at 0.67 . Testing of single basalt fibres with diameters of $13 \mu \mathrm{m}$ and $17 \mu \mathrm{m}$ indicates that tensile strength and modulus are independent of diameter, following an improvement in fibre diameter consistency in line with glass fibres.
\end{abstract}

\section{Keywords:}

Basalt fibre, Chemical properties, Mechanical properties, Physical properties 


\section{Introduction}

Environmental issues such as waste and recyclability of composites are becoming increasingly important to industry and government, which has led to the promotion of natural fibres as reinforcement for polymer composites [1-3].Typical fibres used as reinforcement are Glass (GF) or Carbon (CF) because of their high mechanical properties, especially strengths; however, they are not environmentally friendly $[4,5]$. Natural fibres, including vegetal fibres, such as kenaf and flax show low mechanical properties and are prone to thermal degradation $[6,7]$, making them unsuitable to compete with GF and CF. This has led to a focus on basalt fibres (BF). Continuous basalt fibres have a simple manufacturing process requiring no additives as seen with GF [8]. It consists of melting basalt rock at temperatures between 1350 and $1700^{\circ} \mathrm{C}$ [9] and then pulling the molten material downwards through a platinum-rhodium die (bushing) via the spinneret method. The melting of basalt rock is conducted in two stages: firstly it is fused in the initial furnace and then transferred to the primary furnace which controls the temperature of the melt and feeds the bushings [10]. Heating of glass fibre materials for processing is achieved primarily by overhead gas heaters. For basalt, the dark colour absorbs the infrared energy from these gas burners close to the surface of the melt, creating difficulties in obtaining a homogeneous melt. There are two methods to overcome this; holding the basalt melt in the heating stage for longer or more commonly by using immersed electrodes to electrically heat the melt $[10,11]$. Due to the nature of basalt rock its chemical composition can vary depending on the geographical location and conditions of source. Basalt is a chemical rich rock consisting primarily of silicon, aluminium, calcium and iron oxides, not unlike glass fibre [12-14]. Fibres produced from basalt comprise of olivine, plagioclase, pyroxene and clinopyroxene minerals [15]. Basalt is classed according its $\mathrm{SiO}_{2}$ content where alkaline basalts contain up to $42 \% \mathrm{SiO}_{2}$, mildly acidic basalt contains $43-46 \% \mathrm{SiO}_{2}$ and acidic basalt contain over $46 \%$ $\mathrm{SiO}_{2}$. To manufacture continuous basalt fibre, the basalt rock must fall within the acidic class $(>46 \%$ $\mathrm{SiO}_{2}$ ) [16]. Recent research [17] has shown that the melting properties of basalt used for manufacture varies depending on the mineral class of the basalt rock. The melting process is a crucial stage of continuous basalt fibre (CBF) production where homogeneity of the melt can have effects on the quality, fibre diameter and performance stability of basalt fibre. The ability to produce BF with consistent fibre diameter is significant in order to compete with fibres such as glass. Significant 
variations in fibre diameter will affect quality, the ability to model basalt composites, fibre volume fraction and potentially interfacial adhesion through increased or reduced surface area $[18,19]$. Basalt fibres demonstrate superior mechanical properties compared to vegetal fibres and compare, or are higher, to those of glass $[3,18,20]$. The density of basalt is between $2.6-2.7 \mathrm{~g} / \mathrm{cm}^{3}$ whereas EGlass density is $2.5-2.6 \mathrm{~g} / \mathrm{cm}^{3}$ [21]. Basalt fibres are further characterised by excellent sound insulation, thermal resistance higher than that of glass, good chemical resistance to both acidic and alkaline conditions (higher than E-glass) and biologically inert [12,22,23]. The cost of basalt fibres $(\sim £ 6 / \mathrm{kg})$ is currently higher than E-glass $(\sim £ 1.5 / \mathrm{kg})$ though lower than S-glass $(\sim £ 16 / \mathrm{kg})$. E-glass fibre manufacturing costs have economies of scale as an established reinforcement, whereas basalt fibre production costs are compromised by the early stage small scale production. As basalt rock is the most common bedrock on earth there is an abundant supply available; however, as basalt fibre requires a certain level of $\mathrm{SiO}_{2}$ content there are currently approximately three dozen mines and quarries that have certified rock that is suitable for fibre manufacture with the most common found in Ukraine and Russia [24]. These factors, together with its environmentally friendly nature [25], mean it displays significant potential as a competitor or replacement of glass fibres and a new fibre for various applications. As a result, short and continuous basalt fibres have been the focus of recent research with an aim to identify their potential applications [12,21,26-34].

With the increased demand for basalt, there has been an increase in the number of basalt fibre manufacturers becoming established. Glass fibres have a relatively standardised performance whereas the performance and quality of basalt fibre from different sources or manufacturers is not yet been fully examined; therefore it is important to understand the variations of basalt fibre from different manufacturers; such as chemical composition, diameter consistency and mechanical properties. Therefore the aim of this paper is to analyse these factors and to determine if there are any variations or relationships between each of these factors.

\section{Materials and methods}

\section{Materials}

Several types of commercial basalt fibres were characterised in this study alongside commercially available glass fibre for comparison purposes. Fibres used are indicated in Table 1. Each fibre was provided in direct roving form with a general purpose sizing which is primarily suitable for epoxies. 
Company $\mathrm{A}$ and $\mathrm{C}$ were chosen due to their long establishment and are classed amongst world leaders in basalt fibre manufacture while Company B is relatively new (5 Years) and fast emerging competitor within the market. Similarly, E-glass was selected from Company D as they are a well established glass fibre manufacturer.

Table 1 Basic data of investigated fibre

\begin{tabular}{lcccc}
\hline Designation & Fibre Type & Manufacturer & Nominal Diameter $(\mu \mathrm{m})$ & Linear Density (Tex) \\
\hline BF1 & Basalt & Basaltex & 13 & 150 \\
BF2 & Basalt & Mafic & 13 & 300 \\
BF3 & Basalt & GBF & 13 & 400 \\
BF4 & Basalt & Basaltex & 17 & 600 \\
BF5 & Basalt & Mafic & 17 & 500 \\
GF & Glass & PPG & 14 & 300 \\
\hline
\end{tabular}

Methods

X-ray fluorescence analysis

The chemical composition of fibres was determined through X-ray fluorescence (XRF) analysis. Fibres were initially placed in a muffle furnace at $\mathrm{T}=650^{\circ} \mathrm{C}$ for 30 minutes to remove any sizing present on the fibres. Pyrolysis is a commonly used method for the removal of sizing with the used temperatures and time showing to be higher than the temperature required to remove all organic sizing [35-37]. After cooling, the de-sized fibres were milled using a Retsch PM100 planetary ball milling machine for two minutes at $520 \mathrm{rpm}$ in order to achieve a consistent powder form. Powder fibre samples were mixed with CEREOX® Licowax (Fluxana, BM-0002) at a ratio of 4:1 to bind the powder together and then pressed (Retsch PP25) to produce pellets for analysis. CEREOX was used as a binding agent as it is clean and stable under $\mathrm{x}$-rays and designed specifically for XRF as it does 
not influence results. XRF was performed using a Thermo Scientific Niton FXL FM-XRF analyser. Each sample was tested in three spots with a testing time of 150 seconds per spot.

Fibre diameter analysis

To determine the actual fibre diameter of basalt and glass samples, a Scanning Electron Microscope (SEM) was used (JEOL JSM-6010) to perform measurements. Fibres were firstly gold coated to improve image quality and accuracy. A set of 100 measurements were recorded from $15 \mathrm{~mm}$ samples taken at 1 metre intervals, along the roving length, to total 300 measurements per fibre type. Fibre sizing was not removed prior to measurements since the calculated sizing thickness was less than $16 \mathrm{~nm}$ and therefore negligible. SEM was used over standard optical microscopy due to its increased image quality.

Mechanical testing

Single fibre tensile tests were performed according ASTM D3379 using an Instron 5564 with a 200N loadcell. As received fibres were separated and bonded to cardboard templates, clamped in the grips of the test machine, then the template was carefully cut before test start. A minimum of 10 tests for each sample were performed at a constant crosshead rate of $1 \mathrm{~mm} / \mathrm{min}$ for 25,50 and $100 \mathrm{~mm}$ gauge lengths. As it was not possible to use an extensometer or strain gauges due to the small diameter and fragile fibres, the load vs displacement recorded by the Instron was used in conjunction with the compliance method stated within ASTM D3379. Indicated compliance was first calculated using Eq. (1).

$C_{a}=(I / P) x(H / S)$

Where I = total extension for straight line section of load-time curve, extrapolated across full chart scale, $\mathrm{P}=$ full scale force, $\mathrm{H}=$ crosshead speed and $\mathrm{S}=$ chart speed. True compliance is then calculated as:

$C=C_{a}-C_{s}$

Where $C_{s}=$ system compliance. The Young's modulus is calculated as a corrected value using the following equation:

$E=L / C A$

Where $L=$ specimen gauge length and $A=$ average filament area. 


\section{Results and Discussion}

The chemical composition of studied fibres can be seen in Table 2. The primary compound found within both basalt and E-glass fibres is $\mathrm{SiO}_{2}$, with basalt fibres having a relatively consistent proportion between 48.82 and 49.69 mass percent (mass\%) across different manufacturers, consistent with the requirements to spin continuous basalt fibres. Glass fibres had a higher $\mathrm{SiO}_{2}$ content at over 53 mass $\%$ which is in agreement with previous studies and specifications [9,12,38,39]. Basalt fibres contain five essential elemental groups of: $\mathrm{SiO}_{2}, \mathrm{Al}_{2} \mathrm{O}_{3}, \mathrm{CaO}, \mathrm{MgO}$ and $\mathrm{Fe}_{2} \mathrm{O}_{3}$. Similarly, glass fibres were found to be mainly formed from five primary groups consisting of: $\mathrm{SiO}_{2}, \mathrm{Al}_{2} \mathrm{O}_{3}, \mathrm{CaO}, \mathrm{MgO}$ and $\mathrm{B}_{2} \mathrm{O}_{3}$. Measurements of Boron were not within the scope of equipment used, however it is known that glass fibres still contain Boron in the $0.4-5$ mass $\%$ range, with the exception of some new boron-free glass fibres, but is not present in basalt $[9,38,40,40,41]$. Glass fibres shared further oxides with basalt fibres, e.g $\mathrm{TiO}_{2}, \mathrm{~K}_{2} \mathrm{O}, \mathrm{Na}_{2} \mathrm{O}$ and $\mathrm{Fe}_{2} \mathrm{O}_{3}$, however in much lower quantities $(<1$ mass $\%)$ than basalt. These elements highlight the chemical differences between glass and basalt fibres with the higher content of $\mathrm{Fe}_{2} \mathrm{O}_{3}$ contributing to the increased temperature resistance and darker colour of basalt fibre. With the exception of a small variation seen in $\mathrm{SiO}_{2}$ and $\mathrm{Al}_{2} \mathrm{O}_{3}$ content ( 1 1 mass $\%), B F 1$ and BF2 have a very similar chemical composition. On the other hand, BF3 has a very similar $\mathrm{SiO}_{2}$ content to $\mathrm{BF} 1$ and $\mathrm{BF} 2$ but varies consistently by $1-2$ mass $\%$ for all other elements. Higher content of $\mathrm{CaO}$ reduces the melting temperature of basalt and thus allowing easier homogenisation of the melt, known to aid fibre production [42]. BF1 and BF2 have a very similar content of $\mathrm{CaO}$ whereas $\mathrm{BF} 3$ is $\sim 1.25 \%$ lower which may result in an inhomogeneous melt unless accounted for in furnace temperature.

Table 2 Chemical composition of basalt and glass fibres

\begin{tabular}{|c|c|c|c|c|c|c|c|c|c|}
\hline \multirow[b]{2}{*}{ Element } & \multirow[b]{2}{*}{ Oxide } & \multicolumn{2}{|c|}{ BF1 } & \multicolumn{2}{|c|}{ BF2 } & \multicolumn{2}{|c|}{ BF3 } & \multicolumn{2}{|c|}{ GF } \\
\hline & & $\begin{array}{l}\text { Element } \\
\text { mass } \%\end{array}$ & $\begin{array}{c}\text { Oxide } \\
\text { mass } \%\end{array}$ & $\begin{array}{c}\text { Element } \\
\text { mass } \%\end{array}$ & $\begin{array}{c}\text { Oxide } \\
\text { mass } \%\end{array}$ & $\begin{array}{c}\text { Element } \\
\text { mass } \%\end{array}$ & $\begin{array}{c}\text { Oxide } \\
\text { mass } \%\end{array}$ & $\begin{array}{c}\text { Element } \\
\text { mass } \%\end{array}$ & $\begin{array}{c}\text { Oxide } \\
\text { mass } \%\end{array}$ \\
\hline Si & $\mathrm{SiO}_{2}$ & 22.52 & 48.82 & 23.22 & 49.69 & 23.26 & 49.58 & 24.78 & 53.02 \\
\hline $\mathrm{Al}$ & $\mathrm{Al}_{2} \mathrm{O}_{3}$ & 6.79 & 12.83 & 7.12 & 13.45 & 6.11 & 11.54 & 5.91 & 11.16 \\
\hline $\mathrm{Ca}$ & $\mathrm{CaO}$ & 4.50 & 6.02 & 4.51 & 6.03 & 3.62 & 4.85 & 12.53 & 16.77 \\
\hline $\mathrm{Fe}$ & $\mathrm{Fe}_{2} \mathrm{O}_{3}$ & 5.18 & 7.41 & 5.25 & 7.51 & 4.87 & 6.96 & 0.17 & 0.24 \\
\hline $\mathrm{Mg}$ & $\mathrm{MgO}$ & 2.45 & 4.06 & 2.03 & 3.36 & 3.08 & 5.10 & 1.82 & 3.02 \\
\hline $\mathrm{Ti}$ & $\mathrm{TiO}_{2}$ & 0.56 & 1.18 & 0.58 & 1.21 & 0.43 & 0.90 & 0.05 & 0.10 \\
\hline $\mathrm{K} \& \mathrm{Na}$ & $\begin{array}{r}\mathrm{K}_{2} \mathrm{O} \\
+\mathrm{Na}_{2} \mathrm{O} \\
\end{array}$ & 1.12 & 2.44 & 1.20 & 2.50 & 1.67 & 2.13 & 0.27 & 0.36 \\
\hline
\end{tabular}


Fibre from BF2 was chosen for further investigation to determine the consistency of fibre manufacture over time. Details of the fibres tested and results are seen in Table 3. Fibres batches were manufactured approximately one year apart from each other. It is noted that the average measured diameter does not vary significantly between each year; however, a clear change in standard deviation is evident with an improvement from 1.33 to 0.61 . This deviation value clearly shows considerably improvements in the consistency of fibre manufacture. Fibre diameter is related to parameters such as velocity of molten material, haul off rate and internal diameter of the bushing [43]. For basalt fibre, it is believed that improvements in the melt homogeneity resulted in better control of the fibre diameter, as seen with glass fibres [44].

Table 3 Results of fibre diameter measurements for BF2

\begin{tabular}{lcccc}
\hline Manufacturer & $\begin{array}{c}\text { Date of } \\
\text { Manufacture } \\
(\mathrm{MM}-\mathrm{YY})\end{array}$ & $\begin{array}{c}\text { Stated } \\
\text { Diameter }\end{array}$ & $\begin{array}{c}\text { Measured } \\
\text { Diameter }\end{array}$ & $\begin{array}{c}\text { Standard } \\
\text { Deviation }\end{array}$ \\
& $02-14$ & 13 & 13.39 & 1.33 \\
Mafic & $04-15$ & 13 & 13.43 & 1.10 \\
& $08-16$ & 13 & 13.31 & 0.61 \\
\hline
\end{tabular}

The improved results of BF2 were then compared to fibre diameter measurements of tested fibres from other manufacturers, seen in Table 4. In addition to fibres tested in this work, results have been compared to previous studies on Technobasalt and D.S.E Group fibres designated BF6 and BF7 respectively [45]. The stated nominal diameter by manufacturers of basalt fibres was $13 \mu \mathrm{m}$ across all samples. Glass fibres were measured at $13.87 \mu \mathrm{m}$ to the stated $14 \mu \mathrm{m}$ diameter with a low standard deviation of 0.67 . Diameter consistency of basalt fibres is necessary for them to be competitive against glass fibres and to assist in the prediction and modelling of basalt composites. Fibre diameter distribution profile for each test fibre can be seen in Fig.1. 


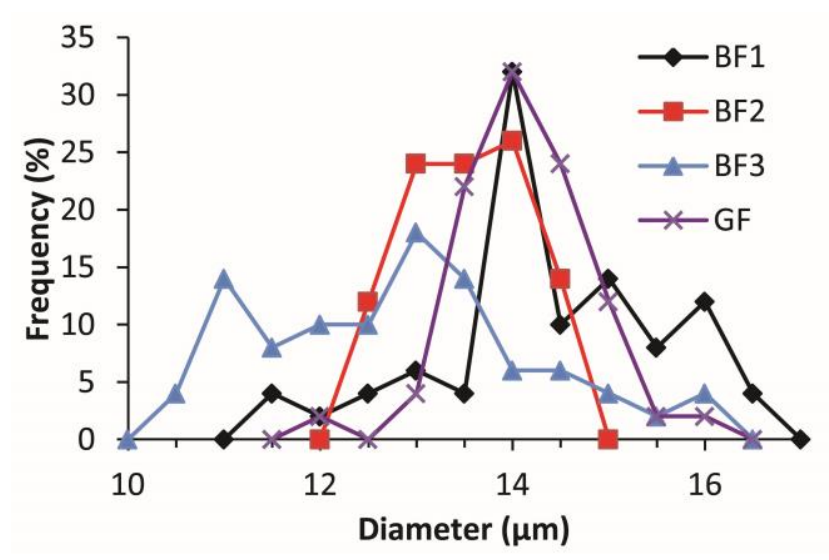

Fig.1 Diameter distribution of basalt and glass fibres

Fibre from one of the leading basalt manufacturers (BF1) was on average $1.16 \mu \mathrm{m}$ larger than specified combined with a higher deviation of 1.2. Although BF3 was close to its stated diameter its deviation was more than double that of glass fibres. BF6 fibres were more than a micron larger than specified with a very high deviation of 2.9 , suggesting a poor consistency in fibre manufacture. These results highlight the current gap between glass and basalt fibres in terms of fibre manufacture and quality. However, the improved fibre of BF2 demonstrated significant improvements with a diameter close to that stated and more importantly a standard deviation of 0.61 , lower than that of glass samples. It is clear there have been some significant improvements in the manufacture and quality of basalt fibre in recent years. Larger diameter fibres BF4 and BF5 show a high diameter consistency with a standard deviation of 0.83 and 0.69 respectively, although this is expected to be a result of easier manufacturer of larger fibres.

Table 4 Results of fibre diameter measurements

\begin{tabular}{lcccc}
\hline Sample & $\begin{array}{c}\text { Stated } \\
\text { Diameter } \\
(\mu \mathrm{m})\end{array}$ & $\begin{array}{c}\text { Average } \\
\text { Diameter } \\
(\mu \mathrm{m})\end{array}$ & $\begin{array}{c}\text { Standard } \\
\text { Deviation }\end{array}$ & $\begin{array}{c}\text { Coefficient } \\
\text { of Variation } \\
(\%)\end{array}$ \\
\hline BF1 & 13 & 14.16 & 1.20 & 8.46 \\
BF2 & 13 & 13.31 & 0.61 & 4.61 \\
BF3 & 13 & 12.61 & 1.38 & 10.97 \\
BF6[45] & 13 & 14.1 & 2.9 & 4.76 \\
BF7 [45] & 13 & 12.70 & 1.50 & 4.00 \\
GF & 14 & 13.87 & 0.67 & 4.84 \\
\hline
\end{tabular}


The tensile strength and tensile modulus of all $13 \mu \mathrm{m}$ fibres are presented in Fig.2(a) and Fig.2(b) respectively. Initial observation of the tensile strength indicates that fibre strength decreases as the fibre length increases for all fibres. This behaviour is widely associated with an increase in flaw population due to the longer fibre length and has been observed in both carbon and glass fibres $[46,47]$.

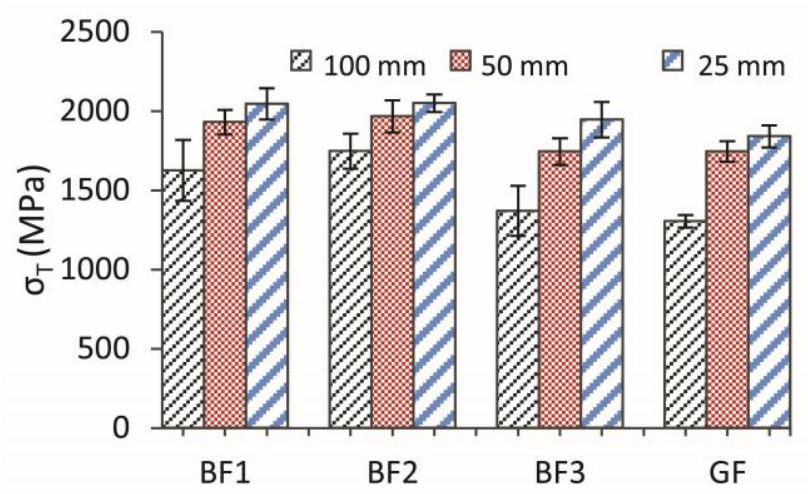

(a)Tensile strength

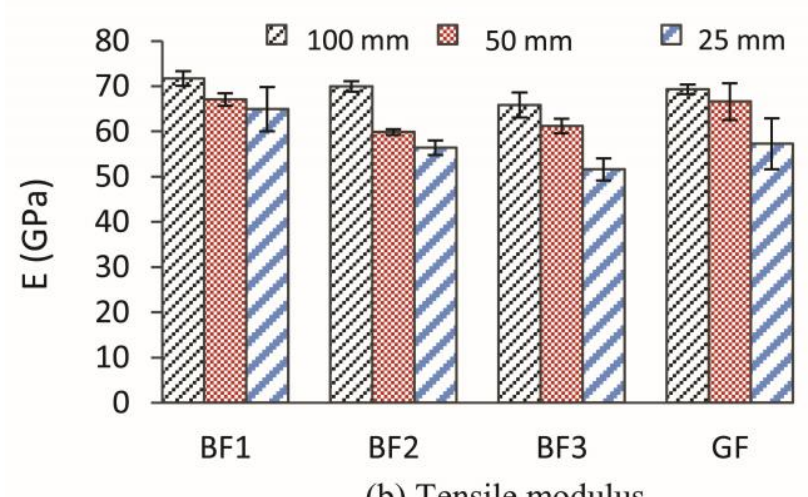

(b) Tensile modulus

Fig.2 Tensile properties of $13 \mu \mathrm{m}$ basalt and glass fibres

There are two variables present within these samples which may influence the mechanical properties; these are fibre type/manufacturer and fibre length. Two-way ANOVA was performed in order to determine the dependence of tensile strength and modulus of filaments on these two factors [48]. The pre-requisite of ANOVA to determine the equality of variances was determined by the Levene test [49]. The test statistic $W$ was calculated by: 


$$
W=\frac{(N-k)}{(k-1)} \frac{\sum_{i=1}^{k} N_{i}\left(\bar{Z}_{i}-\overline{\bar{Z}}\right)^{2}}{\sum_{i=1}^{k} \sum_{j=1}^{N_{i}}\left(Z_{i j}-\bar{Z}_{i}\right)^{2}}
$$

Where $k$ is the number of different groups, $N$ is the total number of measurements, $Z_{i j}=\left|Y_{i j}-\bar{Y}_{i}\right|$ where $\bar{Y}_{i}$ is the mean of the $i$-th group and $Y_{i j}$ is the value of the measured variable for the $j$-th case of the $i$-th group, $\overline{\bar{Z}}$ is the mean of all $Z_{i j}, \bar{Z}_{i}$ is the mean of the $Z_{i j}$ for the $i$-th group. The resulting $P$ values for tensile strength and tensile modulus were 0.23 and 0.49 , which are significantly higher than the significance level $\alpha=0.05$. Therefore the null hypothesis theory of standard variations can be accepted. ANOVA was then performed with the fibre type being Factor $A$ and fibre length being Factor B. Calculated $P$-values from ANOVA were used as results considering a significance level of $\alpha=0.05$. The null hypothesis of equal means is accepted when $P>\alpha$ and hence rejected when $P<\alpha$.

Table 5 Two-way ANOVA results for tensile properties of basalt fibres

\begin{tabular}{llllll}
\hline & & \multicolumn{2}{c}{ Tensile strength } & \multicolumn{2}{c}{ Tensile modulus } \\
\cline { 3 - 6 } Sample & Degrees of freedom & $F$ & $P$ value & $F$ & $P$ value \\
\hline Factor A (fibre type) & 2 & 8.48 & 0.0364 & 9.46 & 0.0305 \\
Factor B (fibre length) & 2 & 28.28 & 0.0044 & 16.38 & 0.0118 \\
Interaction & 4 & 18.38 & 0.0077 & 12.92 & 0.0147 \\
\hline
\end{tabular}

Results of two-way ANOVA for tensile strength and tensile modulus are reported in Table 5. The reported $\mathrm{F}$ value is the variation between sample means/variation within the samples and is used for determining $P$-value. For tensile strength the very low $P$ value relating to the fibre length shows that variations in gauge length are relevant at the $5 \%$ significance level, indicating a strong dependence of strength on gauge length. Low $P$ values for Factor $A$ also indicated a dependence of fibre strength on the fibre type/manufacturer. Previous studies have further confirmed the strong dependence of basalt fibre strength on gauge length [15] yet indicated there was no dependence on fibre type. When the lower values of BF3 were removed from ANOVA analysis, the corresponding $P$ value for fibre type increased to 0.5 which is in agreement with previous findings and highlighting the poor mechanical performance of BF3 fibres. However as BF3 is a commercially available fibre it is important to include it into the analysis, hence, it can be suggested there is a dependence of tensile strength on the fibre type. 
A similar trend for tensile modulus can be seen from ANOVA results. The low $P$ values for both Factor A and Factor B show that elastic modulus has a dependence on both fibre type and fibre length. It has previously been suggested [15] that there was no dependence of modulus on fibre length. This change may be explained by the gauge lengths used during testing which have earlier focused on $10-40 \mathrm{~mm}$. When values for $100 \mathrm{~mm}$ gauge length are removed from ANOVA analysis, the corresponding $P$ value for fibre length increases to 0.16 and therefore indicates the tensile modulus across different fibre lengths is not significantly different. However, comparable testing performed on E-Glass fibres [43] with lengths of $5-80 \mathrm{~mm}$ showed that tensile modulus increased as the fibre length increased, in agreement with the results found for longer basalt fibres. This increase, despite modulus correction, can be attributed to test equipment's dependency on sample gauge length. This dependency is manifested as an elastic deformation contribution from the testing equipment and is in agreement with the work of Pardini and Manhani [47] who saw an increase in modulus with gauge length for both glass and carbon fibres with the ASTM correction method and the rigidity method. Comparisons between glass and basalt fibres show that basalt is characterised by a higher tensile strength and a comparable elastic modulus as that of glass. It is noted that the mechanical properties are lower than values stated in the technical data sheet.

Tensile data was further analysed by applying Weibull statistics. Data for each fibre and each gauge length was sorted in ascending order. From this, the corresponding value of cumulative failure probability, $P_{F}$, was determined using the median rank estimator [50].

$$
P_{F}=\frac{i-0.3}{N+0.4}
$$

where $i$ is the ith term of total number of tests $N$. The Weibull parameters $m$ (shape) and $\sigma_{o}$ (scale) were determined for each fibre manufacturer and gauge length by fitting data points with the twoparameter Weibull distribution in Eq. (6).

$$
\ln \left[-\ln \left(1-P_{F}\right)\right]=m \ln (\sigma)-m \ln \left(\sigma_{o}\right)
$$

The Weibull plots obtained from Eq. (6) for BF2 fibres are reported in Fig.3. The obtained parameters $m$ and $\sigma_{o}$ for all fibres and lengths are shown in Table 6 . Lower values of $m$ for BF3 suggest that flaws are less evenly distributed throughout the fibre and thus resulting in a greater scatter in strength [47,50,51]. Fibres BF1 and BF2 have very similar values with the exception of $100 \mathrm{~mm}$ lengths where 
the $\mathrm{m}$ value for $\mathrm{BF} 1$ is considerably lower indicating a less homogeneous material over longer lengths.

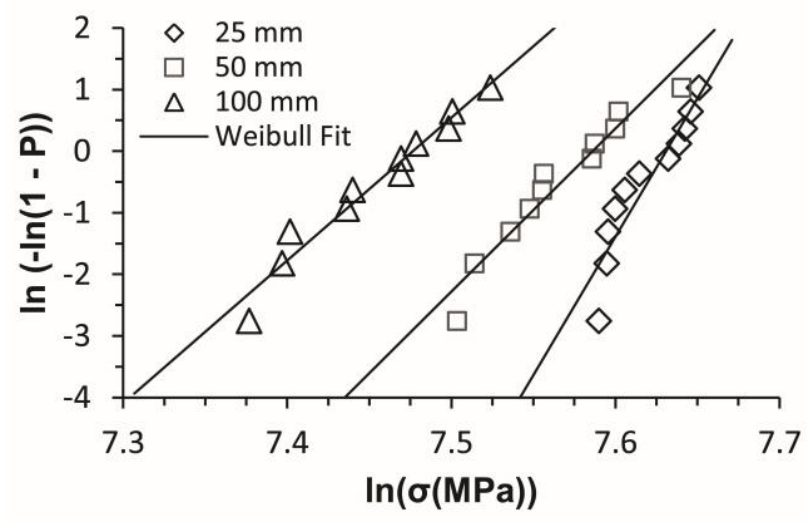

Fig.3 Weibull plot for fibres BF2

Table 6 Weibull parameters for strength of $13 \mu \mathrm{m}$ basalt fibres

\begin{tabular}{lllllll}
\hline \multirow{2}{*}{ Fibre } & \multicolumn{2}{c}{$25 \mathrm{~mm}$} & \multicolumn{2}{c}{$50 \mathrm{~mm}$} & \multicolumn{2}{c}{$100 \mathrm{~mm}$} \\
& $\sigma_{o(\mathrm{MPa})}$ & $m$ & $\sigma_{o(\mathrm{MPa})}$ & $m$ & $\sigma_{o(\mathrm{MPa})}$ & $m$ \\
\hline BF1 & 2065 & 38.19 & 1942 & 31.63 & 1730 & 12.71 \\
BF2 & 2066 & 42.52 & 1971 & 26.38 & 1765 & 25.69 \\
BF3 & 1972 & 18.56 & 1775 & 32.18 & 1477 & 15.67 \\
\hline
\end{tabular}

Furthermore, as Weibull parameters were obtained at different gauge lengths it allows for the predictions of tensile strength at lengths outside of the experimental range [52]. This can be achieved using Eq. (7), in particular at a cumulative probability failure $P_{F}=0.5$.

$$
\sigma=\sigma_{o}\left[\frac{1}{A_{o} L_{f}} \ln 2\right]^{1 / m}
$$

where $A_{o}$ is the cross section area and $L_{f}$ is the gauge length of the fibre. The resulting plot obtained using the parameters from Table 6 are reported in Fig.4. It is observed that the predictions from Weibull statistics for BF1 and BF2 are very similar with an exception for BF3, in agreement with ANOVA in Table 5, high-lighting that there can be a difference between the strength of fibres from different manufacturers. 


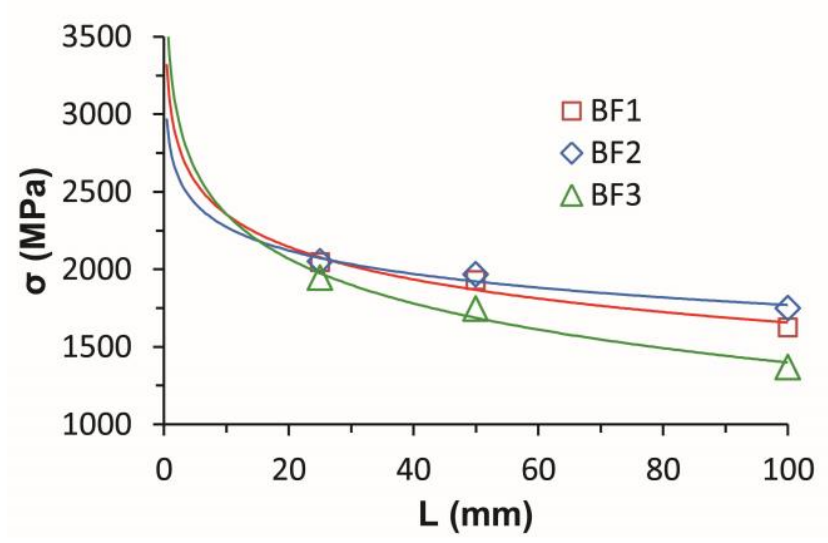

Fig.4 Tensile strength of $13 \mu \mathrm{m}$ basalt fibres as a function of gauge length

The mechanical properties of $17 \mu \mathrm{m}$ fibre from Company B (BF5) and A (BF4) are presented in Fig.5. Fibres of $17 \mu \mathrm{m}$ show the same trend as $13 \mu \mathrm{m}$ fibre in that the tensile strength increases as fibre length decreases and the tensile modulus increases as the length is increased.
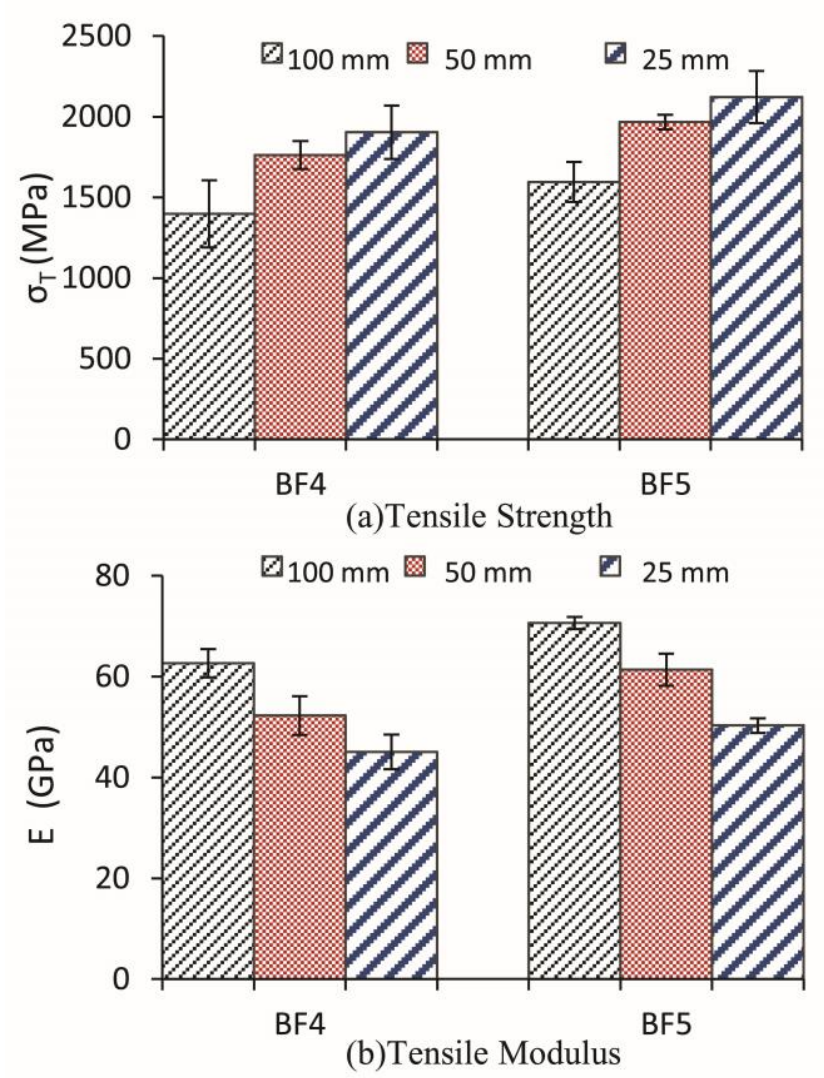

Fig.5 Tensile properties of $17 \mu \mathrm{m}$ basalt and glass fibres 
Weibull statistics was performed again for $17 \mu \mathrm{m}$ fibres. The $\mathrm{m}$ and $\sigma_{\circ}$ Weibull parameters are shown in Table 7 while the prediction of strength at different lengths from Eq. (7) is presented in Fig.6.

Table 7: Weibull parameters for strength of $17 \mu \mathrm{m}$ basalt fibres

\begin{tabular}{|c|c|c|c|c|c|c|}
\hline \multirow{2}{*}{ Fibre } & \multicolumn{2}{|c|}{$25 \mathrm{~mm}$} & \multicolumn{2}{|c|}{$50 \mathrm{~mm}$} & \multicolumn{2}{|c|}{$100 \mathrm{~mm}$} \\
\hline & $\sigma_{o(\mathrm{MPa})}$ & $m$ & $\sigma_{o \text { (MPa) }}$ & $m$ & $\sigma_{o \text { (MPa) }}$ & $m$ \\
\hline BF4 & 1962 & 13.32 & 1797 & 28.6 & 1476 & 20.2 \\
\hline BF5 & 2210 & 20.2 & 2001 & 47.64 & 1634 & 15.66 \\
\hline
\end{tabular}

Unlike $13 \mu \mathrm{m}$ fibres there is a notable difference in strength between the $17 \mu \mathrm{m}$ fibres BF4 and BF5. BF4 has a consistently lower $\mathrm{m}$ value at 25 and $50 \mathrm{~mm}$ gage lengths and is comparable at $100 \mathrm{~mm}$, indicating BF5 to have a better homogeneity [50]. At $100 \mathrm{~mm}$ the $\mathrm{m}$ value drops for both fibres confirming that it is more likely to encounter critical fibre flaws at longer gauge lengths. The performance difference between BF4 and BF5 is further seen in Fig.6.

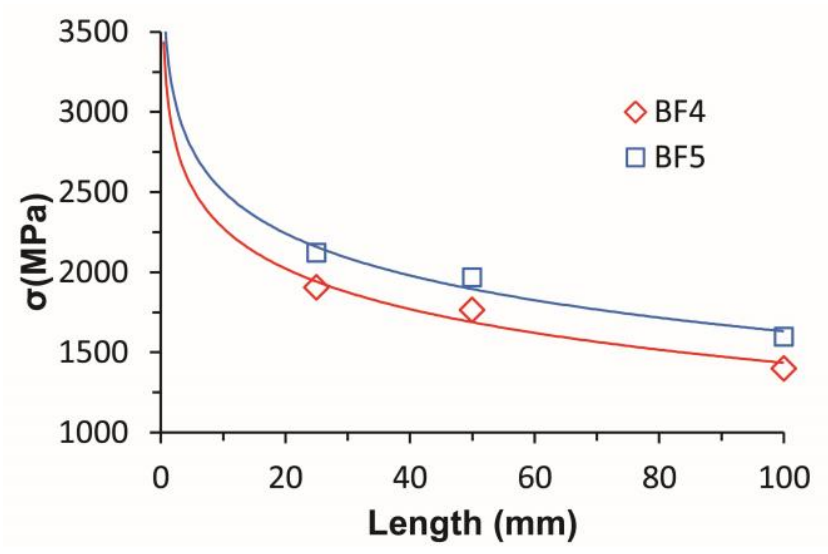

Fig.6 Tensile strength of $17 \mu \mathrm{m}$ basalt fibres as a function of gauge length

It has widely been thought that the tensile strength and modulus of natural fibre increases as the fibre diameter decreases [53-56]. This has been proven true by fibre from Company $A$ where there is a clear decrease in tensile strength and tensile modulus as the fibre diameter is increased, Fig.7(a) and Fig.8(a). Contrary to this belief, it has been shown that tensile properties of glass do not depend on fibre diameter due to improvements and consistency in the manufacture of glass fibre [57]. 
Comparisons of tensile strength and tensile modulus between $13 \mu \mathrm{m}$ and $17 \mu \mathrm{m}$ basalt fibre from Company B (BF2 and BF5) can be seen in Fig.7(b) and Fig.8(b).

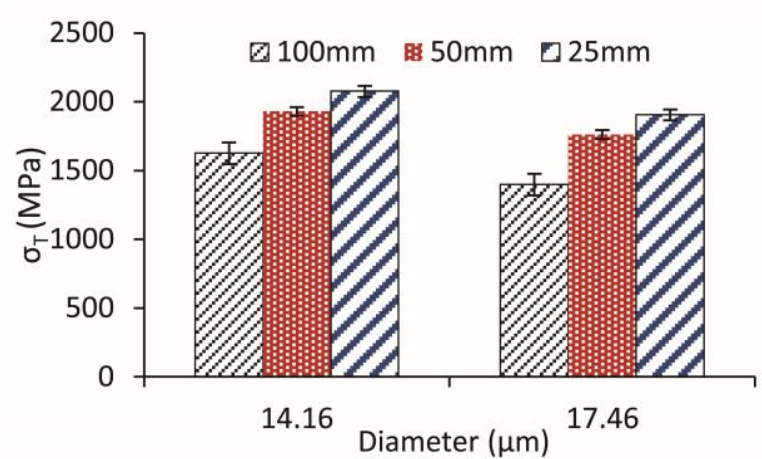

(a) Company A

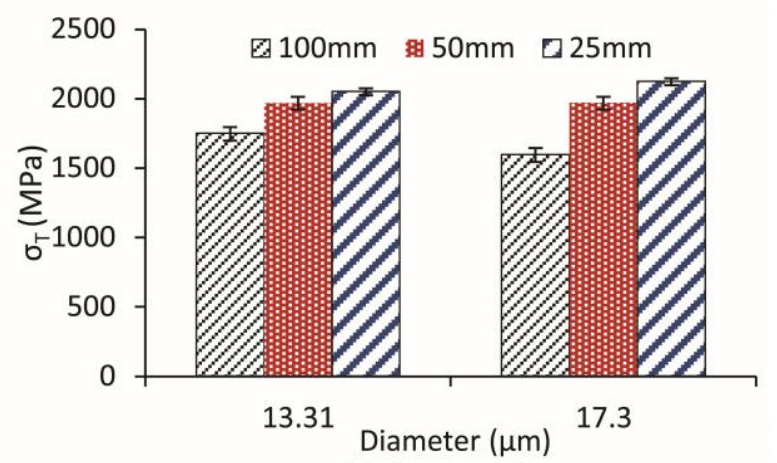

(b) Company B

Fig.7 Diameter - Tensile strength for (a) BF4 and (b) BF5
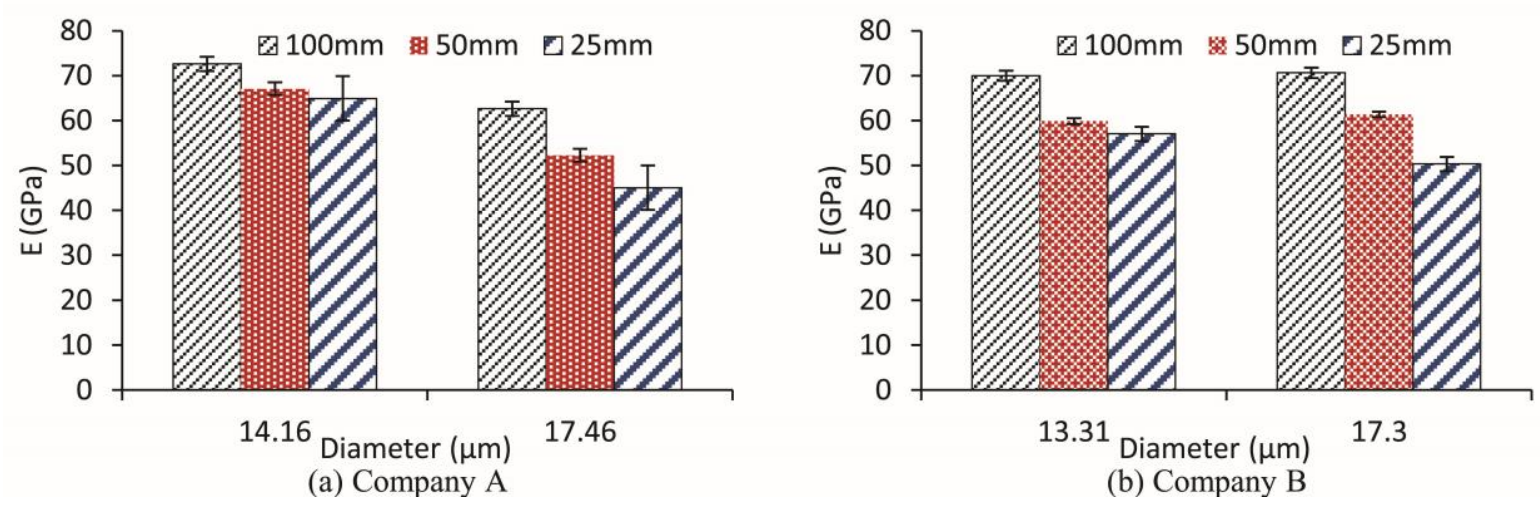

Fig.8 Diameter - Tensile modulus for (a)BF4 and (b) BF5

The tensile strength between the two fibre diameters of BF2 and BF5 is near constant with the exception of the longer $100 \mathrm{~mm}$ lengths, where a slight reduction in strength is seen in the larger diameter. The cause for this difference is unknown however; in longer fibre lengths it is more probable to encounter critical fibre flaws, which may be more prominent with larger diameters. Tensile modulus for BF5 had little deviation showing to be independent of fibre diameter.

The demonstrated independence of fibre strength from diameter for Company B is in agreement with previous work [45]. Otto [57] demonstrated that when fibres of different diameter are formed under controlled, near identical conditions their break strengths are identical and hence reliant on the forming process rather than diameter, which applies for diameters larger than $9 \mu \mathrm{m}$. With the 
demonstrated increase in quality of basalt manufacture for fibre from Company $\mathrm{B}$, basalt fibres have shown to behave in a similar manner. These findings apply only to fibre on its own and not fibres embedded in a polymer matrix. Fibres tows consisting of fibres with a smaller diameter but constant weight have an increased surface area which in turn generates more interaction and adhesion to the matrix resulting in higher mechanical performance [19]. However, as the fibres can now start off with the same mechanical properties it is thought that the effect of surface area may not be as large as fibres that have a different performance at varying diameters.

The mechanical properties of basalt and glass fibres have been related to their chemical composition. As a result, it has been attempted to improve the mechanical properties of basalt fibre through the addition of extra elements to the manufacture, resulting in positive improvements [58]. A relationship between the ceramic like content $\left(\mathrm{SiO}_{2}+\mathrm{Al}_{2} \mathrm{O}_{3}\right)$, which is the primary composition of basalt, and the mechanical properties has been demonstrated; however, a correlation with the $\mathrm{Al}_{2} \mathrm{O}_{3}$ could not be revealed [42]. The relationship between the tensile strength and both the ceramic like content and the $\mathrm{Al}_{2} \mathrm{O}_{3}$ content is presented in Fig.9.

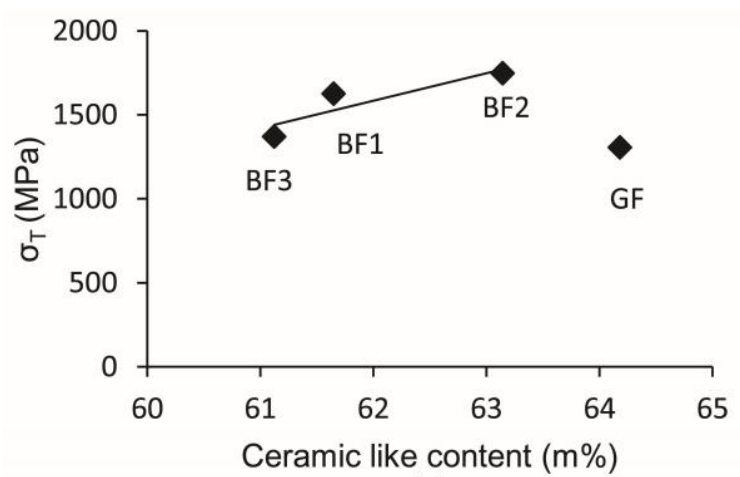

(a)

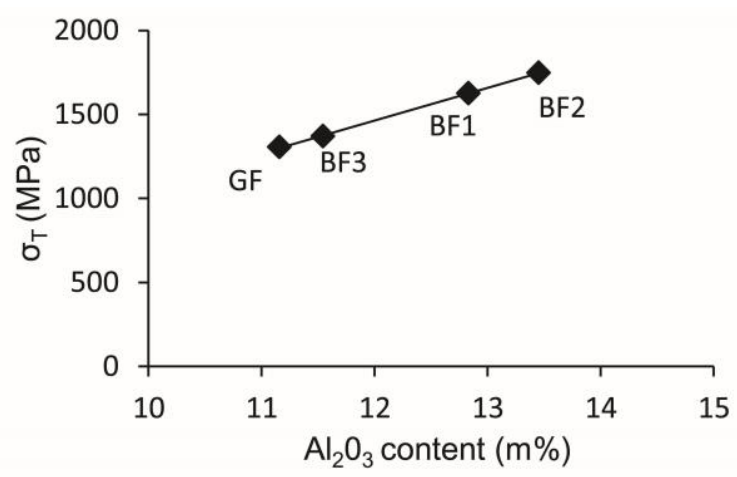

(b)

Fig.9 Chemical Composition - Tensile strength relationships 


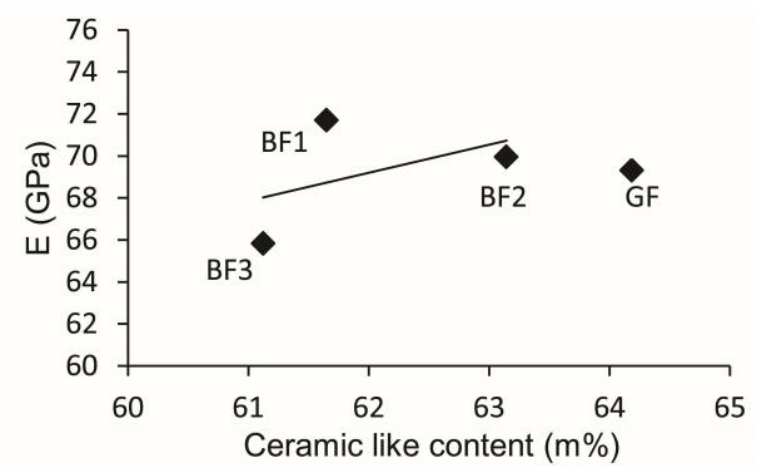

(a)

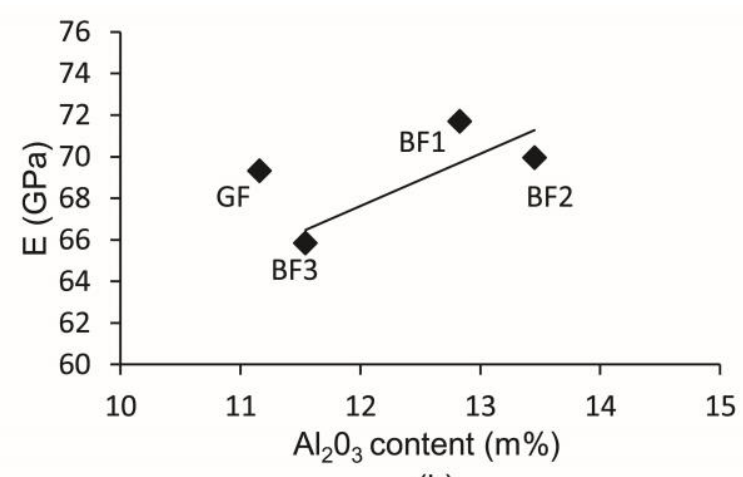

(b)

Fig.10 Chemical composition - Tensile modulus relationships

Although glass was presented on the same graph, it was not included in the correlation due to its differing chemical composition to basalt. There is a clear correlation between tensile strength and the ceramic like content (Fig.9(a)) but also a significant relation with $\mathrm{Al}_{2} \mathrm{O}_{3}$ content (Fig.9(b)). Two-way ANOVA was performed for tensile strength with ceramic content as Factor $\mathrm{A}$ and $\mathrm{Al}_{2} \mathrm{O}_{3}$ as Factor $\mathrm{B}$. Ceramic content generated a $P$ value of 0.001 , below the significant level $\alpha=0.05$. The resulting $P$ value for $\mathrm{Al}_{2} \mathrm{O}_{3}$ was considerably lower at $1.3523 \mathrm{E}-7$, suggesting the tensile strength is more dependent on the $\mathrm{Al}_{2} \mathrm{O}_{3}$ content. Comparisons with the tensile modulus, seen in Fig.10, indicate that there is no significant correlation between the modulus and ceramic like or $\mathrm{Al}_{2} \mathrm{O}_{3}$ content. Similar comparisons of mechanical properties with other elements found within basalt fibre yielded no evident relationships suggesting they have a low importance in directly determining the fibres mechanical properties.

\section{Conclusion}

In this work, the chemical composition, fibre diameter and mechanical properties of different basalt fibres were investigated through XRF, SEM and tensile testing. The main components of basalt fibre were $\mathrm{SiO}_{2}, \mathrm{Al}_{2} \mathrm{O}_{3}, \mathrm{CaO}, \mathrm{MgO}$ and $\mathrm{Fe}_{2} \mathrm{O}_{3}$ with small amounts of $\mathrm{TiO}_{2}, \mathrm{~K}_{2} \mathrm{O}, \mathrm{Na}_{2} \mathrm{O}$. Glass fibres shared similar chemical components/constituents as basalt with the main difference in composition being higher levels of $\mathrm{Fe}_{2} \mathrm{O}_{3}$ in basalt. Chemical composition of basalt between manufacturers remained largely consistent with only fibres $\mathrm{BF} 3$ showing a variation in $\mathrm{Al}_{2} \mathrm{O}_{3}, \mathrm{CaO}, \mathrm{MgO}$. Diameter of basalt fibres varied between manufacturers with most showing a higher deviation compared to glass. Significant improvement in fibre diameter distribution is demonstrated for the first time with fibre BF2 
being comparable to glass fibre standard, suggesting advancements in the quality manufacture of basalt.

It was shown that the mechanical properties of basalt fibre can vary between manufacturers; however, when only fibre from Company A and Company B is considered the properties are comparable. Basalt fibres were characterised by a higher tensile strength than E-glass fibres and a comparable modulus. ANOVA was used to demonstrate the dependence of fibre strength on gauge length where shorter fibre lengths yielded higher tensile strength whereas longer fibre lengths over $50 \mathrm{~mm}$ yielded a higher tensile modulus.

For most commercial basalt fibres tested, basalt showed to have a dependence on fibre diameter. Contrary to common belief, the strength and modulus of basalt fibre has shown for the first time an independence on the fibre diameter for fibres from Company $B$, where fibres ranging from $13-17 \mu \mathrm{m}$ displayed comparable properties. A clear correlation between the mechanical properties and chemical composition of basalt fibres was evident with fibres showing a strong dependence on the ceramic like content $\left(\mathrm{SiO}_{2}+\mathrm{Al}_{2} \mathrm{O}_{3}\right)$ but primarily $\mathrm{Al}_{2} \mathrm{O}_{3}$ content, confirmed by $\mathrm{ANOVA}$, which had previously only been suggested. Basalt fibre technology has reached a point where adoption should no longer constrained by product variability as demonstrated in this study. The cost and performance of fibres currently lies between those for E-glass and S2-glass. The wider adoption of basalt fibres as the reinforcement for composites will require mass production to meet the demand for fibres and should lead to them becoming cost competitive with the established E-glass reinforcement.

\section{Acknowledgements}

The authors would like to thank Ulster University, Northern Ireland Advanced Composites and Engineering (NIACE) Centre and Axis Composites for support and provision of testing equipment, Mafic Basalt for the provision of materials and DEL CAST for funding this project.

\section{Funding}

This work was supported and funded by a Department for Employment and Learning (DEL) CAST award. 


\section{References}

[1]Lopresto V, Leone C, De lorio I. Mechanical characterisation of basalt fibre reinforced plastic. Composites Part B: Engineering 2011 6;42(4):717-723.

[2]AL-Oqla FM, Sapuan SM. Natural fiber reinforced polymer composites in industrial applications: feasibility of date palm fibers for sustainable automotive industry. J Clean Prod 2014 3/1;66(0):347354.

[3]Ku H, Wang $\mathrm{H}$, Pattarachaiyakoop N, Trada $\mathrm{M}$. A review on the tensile properties of natural fiber reinforced polymer composites. Composites Part B: Engineering 2011 6;42(4):856-873.

[4]Das S. Life cycle assessment of carbon fiber-reinforced polymer composites. The International Journal of Life Cycle Assessment 2011;16(3):268-282.

[5]PwC - Sustainable Performance and Strategy. Life cycle assessment of CFGF - COntinuous Filament Glass Fibre Products. 2016.

[6]Arbelaiz A, Fernández B, Ramos JA, Retegi A, Llano-Ponte R, Mondragon I. Mechanical properties of short flax fibre bundle/polypropylene composites: Influence of matrix/fibre modification, fibre content, water uptake and recycling. Composites Sci Technol 2005 8;65(10):1582-1592.

[7]Gassan J, Bledzki A. Thermal degradation of flax and jute fibers. Journal od Applied Polymer Science 2001;82(6):1417-1422.

[8]Bashtannik PI, Kabak Al, Yakovchuk YY. The effect of adhesion interaction on the mechanical properties of thermoplastic basalt plastics. Mechanics of Composite Materials 2003;39(1):85-88.

[9]Militký J, Kovačič V, Rubnerová J. Influence of thermal treatment on tensile failure of basalt fibers. Eng Fract Mech 2002 6;69(9):1025-1033.

[10]Gur'ev V, Neproshin E, I., Mostovoi G, E. The Effect of Basalt Fiber Production Technology on Mechanical Properties of Fiber. Glass Ceramics 2001;58:62-65.

[11]Fourné F. Synthetic Fibers. München, Germany: Carl Hanser Verlag; 1999.

[12]Liu Q, SHaw MT, Parnas RS. Investigation of Basalt Fiber Composite Mechanical Properties for Applications in Transportation. Polymer Composites 2006;27(1):41-48.

[13]Czigány T. Discontinuous Basalt Fiber-reinforced Hybrid Polymer Composites. In: Friedrich K, editor. Polymer Composites: From Nano to Macro-scale München, Germany: Springer Verlag; 2005. p. 309-328.

[14]Czigány T. Trends in Fiber Reinforcements - the Future Belongs to Basalt Fiber. Express Polymer Letters 1 2007:59.

[15]Greco A, Maffezzoli A, Casciaro G, Caretto F. Mechanical properties of basalt fibers and their adhesion to polypropylene matrices. Composites Part B: Engineering 2014 12;67(0):233-238.

[16]Militký J, Kovačič V. Ultimate Mechanical Properties of Basalt Filaments. Textile Research Journal 1996;66:225-229.

[17]Chen X, Zhang Y, Hui D, Chen M, Wu Z. Study of melting properties of basalt based on their mineral components. Composites Part B: Engineering 2017 5/1;116:53-60. 
[18]Fiore V, Scalici T, Di Bella G, Valenza A. A review on basalt fibre and its composites. Composites Part B: Engineering 2015;74:74-94.

[19]Dhand V, Mittal G, Rhee KY, Hui D. A short review on basalt fiber reinforced polymer composites. Composites Part B: Engineering 2015;73:166-180.

[20]Djafari Petroudy SR. 3 - Physical and mechanical properties of natural fibers. In: Fan M, Fu F, editors. Advanced High Strength Natural Fibre Composites in Construction: Woodhead Publishing; 2017. p. $59-83$.

[21]Czigány T. Special manufacturing and characteristics of basalt fiber reinforced hybrid polypropylene composites: Mechanical properties and acoustic emission study. Composites Sci Technol 2006 12/18;66(16):3210-3220.

[22]Landucci G, Rossi F, Nicolella C, Zanelli S. Design and testing of innovative materials for passive fire protection. Fire Saf J 2009 11;44(8):1103-1109.

[23]Wei B, Cao H, Song S. Environmental resistance and mechanical performance of basalt and glass fibers. Materials Science and Engineering: A 2010 7/15;527(18-19):4708-4715.

[24]Ross A. Basalt Fibers: Alternative to Glass? 2006.

[25]Jamshaid H, Mishra R. A green material from rock: basalt fibre - a review. The Journal of The Textile Institute 2016;107(7):932-937.

[26]Botev M, Betchev H, Bikiaris D, Panayiotou C. Mechanical Properties and Viscoelastic Behavior of Basalt Fiber-Reinforced Polypropylene. Journal of Applied Polymer Science 1999;74:523-531.

[27]Bhat T, Chevali V, Liu X, Feih S, Mouritz AP. Fire structural resistance of basalt fibre composite. Composites Part A: Applied Science and Manufacturing 2015 4;71:107-115.

[28]Ding L, Liu X, Wang X, Huang H, Wu Z. Mechanical properties of pultruded basalt fiber-reinforced polymer tube under axial tension and compression. Construction and Building Materials 201810 July 2018;176:629-637.

[29]Pawłowski D, Szumigała M. Flexural Behaviour of Full-scale Basalt FRP RC Beams Experimental and Numerical Studies. Procedia Engineering 2015 2015;108:518-525.

[30]Scalici T, Fiore V, Valenza A. Experimental assessment of the shield-to-salt-fog properties of basalt and glass fiber reinforced composites in cork core sandwich panels applications. Composites Part B: Engineering 20181 July 2018;144:29-36.

[31]Shi J, Wang X, Wu Z, Zhu Z. Fatigue behavior of basalt fiber-reinforced polymer tendons under a marine environment. Construction and Building Materials 201715 April 2017;137:46-54.

[32]Mousa S, Mohamed HM, Benmokrane B, Ferrier E. Flexural behavior of full-scale circular concrete members reinforced with basalt FRP bars and spirals: Tests and theoretical studies. Composite Structures 20181 November 2018;203:217-232.

[33]Zhang X, Gu X, Lv J. Effect of basalt fiber distribution on the flexural-tensile rheological performance of asphalt mortar. Construction and Building Materials 201810 August 2018;179:307314.

[34]Zhang X, Gu X, Lv J, Zhu Z, Ni F. Mechanism and behaviour of fiber-reinforced asphalt mastic at high temperature. International Journal of Pavement Engineering 2018;19(5):407-415. 
[35]Glass Fibers. ASM Handbook, Vol. 21: Composites. ASM Handbook, Vol. 21: Composites ed. Materials Park, OH: ASM International; 2001. p. 27--34.

[36]Kolesov YI, Kudryavtsev MY, Mikhailenko NY. Types and Compositions of Glass for Production of Continuous Glass Fiber (Review). Glass and Ceramics 2001;58(5):197-202.

[37]Vas LM, Pölöskei K, Felh s D, Deák T, Czigány T. Theoretical and Experimental Study of the Effect of Fiber Heads on the Mechanical Properties of Non-continuous Basalt Fiber Reinforced Composites. Express Polym Lett 2007:109-121.

[38]Czigány T, Vad J, Pölöskei K. Basalt Fiber as a Reinforcement of Polymer Composites. Periodica Polytechnica Ser. Mech. Eng. 2005;49:3-14.

[39]Chen K, Zhou N, Liu B, Jin G. Improved mechanical properties and structure of polypropylene pipe prepared under vibration force field. Journal of Applied Polymer Science 2009;114(6):3612-3620.

[40]Yang L, Thomason JL. Effect of silane coupling agent on mechanical performance of glass fibre. Journal of Materials Science 2013;48:1947-1954.

[41]Thomason JL. The influence of fibre properties of the performance of glass-fibre-reinforced polyamide 6,6. Composites Sci Technol 1999 12/1;59(16):2315-2328.

[42]Tamás Deák Tibor Czigány. Chemical Composition and Mechanical Properties of Basalt and Glass Fibers: A Comparison. Textile Research Journal 2009(79):645.

[43]Hitchon JW, Phillips DC. The dependence of the strength of carbon fibres on length. Fibre Science and Technology 1979 May 1979;12(3):217-233.

[44]Pardini LC, Manhani LGB. Influence of the testing gage length on the strength, young's modulus and Weibull Modulus of carbon fibres and glass fibre. Materials Research 2002;5(4).

[45]Macfarland TW. Two-Way Analysis of Variance. New York: Springer-Verlag; 2011.

[46]Lim T, Loh W. A comparison of tests of equality of variances. Computational Statistics \& Data Analysis 199615 July 1996;22(3):287-301.

[47]Nakamura AM, Michel $\mathrm{P}$, Setoh $\mathrm{M}$. Weibull parameters of Yakuno basalt targets used in documented high-velocity impact experiments. Journal of Geophysical Research 2007;112.

[48]Weibull W. A Statistical Distribution Function of Wide Applicability. Journal of Applied Mechanics 1951;18:293-297.

[49]Thomason JL. On the application of Weibull analysis to experimentally determined single fibre strength distributions. Composites Science and Technology 201322 March 2013;77:74-80.

[50]da Costa LL, Loiola RL, Monteiro SN. Diameter depenence of tensile strength by Weibull analysis: Part I bamboo fiber. Materia (Rio J.) 2010;15(2).

[51]Bevitori AB, Da Silva ILA, Lopes FPD, Monteiro SN. Diameter depenence of tensile strength by Weibull analysis: Part II jute fiber . Materia (Rio J.) 2010;15(2).

[52]Summerscales J, Hall W, Virk AS. A fibre diameter distribution factor (FDDF) for natural fibre composites. Journal of Materials Science 2011;46(17):5876-5880.

[53]Lee SM editor. Handbook of Composite Reinforcements, pg-217. : John Wiley \& Sons; 1992. 
[54]Otto WH. Relationship of Tensile Strength of Glass Fiber to Diameter. Journal of the American Ceramic Society 2006;38(3):122-125.

[55]Jung T, Subramanian RV. Strengthening of basalt fiber by alumina addition. Scripta Metallurgica et Materialia 1993 2/15;28(4):527-532. 